OPEN ACCESS

Edited by:

Eytan Wine,

University of Alberta, Canada

Reviewed by:

Patrick van Rheenen,

University Medical Center

Groningen, Netherlands

Moftah Hussin Alhagamhmad,

Al-Arab Medical University, Libya

*Correspondence:

Andrew S. Day

andrew.day@otago.ac.nz

Specialty section:

This article was submitted to

Pediatric Gastroenterology,

Hepatology and Nutrition,

a section of the journal

Frontiers in Pediatrics

Received: 23 September 2020 Accepted: 02 December 2020

Published: 05 March 2021

Citation:

Ho SSC, Ross M, Keenan Jl and Day AS (2021) Fecal Calprotectin in Combination With Standard Blood Tests in the Diagnosis of Inflammatory Bowel Disease in Children.

Front. Pediatr. 8:609279

doi: 10.3389/fped.2020.609279

\section{Fecal Calprotectin in Combination With Standard Blood Tests in the Diagnosis of Inflammatory Bowel Disease in Children}

\author{
Shaun S. C. Ho ${ }^{1}$, Michael Ross ${ }^{1}$, Jacqueline I. Keenan ${ }^{2}$ and Andrew S. Day ${ }^{1 *}$ \\ ${ }^{1}$ Department of Pediatrics, University of Otago, Christchurch, New Zealand, ${ }^{2}$ Department of Surgery, University of Otago, \\ Christchurch, New Zealand
}

Introduction: Fecal calprotectin (FC) is a useful non-invasive screening test but elevated levels are not specific to inflammatory bowel disease (IBD). The study aimed to evaluate the sensitivity, specificity, positive predictive value (PPV) and negative predictive value (NPV) of FC alone or FC in combination with other standard blood tests in the diagnosis of IBD.

Methods: Children aged $<17$ years who had FC (normal range $<50 \mu \mathrm{g} / \mathrm{g}$ ) measured and underwent endoscopy over 33 months in Christchurch, New Zealand were identified retrospectively (consecutive sampling). Medical records were reviewed for patient final diagnoses.

Results: One hundred and two children were included; mean age was 12.3 years and 53 were male. Fifty-eight (57\%) of the 102 children were diagnosed with IBD: 49 with Crohn's disease, eight with ulcerative colitis and one with IBD-unclassified. FC of $50 \mu \mathrm{g} / \mathrm{g}$ threshold provided a sensitivity of 96.6\% [95\% confident interval (Cl) 88.3-99.4\%] and PPV of $72.7 \%$ (95\% Cl 61.9-81.4\%) in diagnosing IBD. Two children with IBD however were found to have $\mathrm{FC}<50 \mu \mathrm{g} / \mathrm{g}$. Sensitivity in diagnosing IBD was further improved to 98.3\% (95\% Cl 90.7-99.1\%) when including FC >50 $\mu \mathrm{g} / \mathrm{g}$ or elevated platelet count. Furthermore, PPVs in diagnosing IBD improved when FC at various thresholds was combined with either low albumin or high platelet count.

Conclusion: Although FC alone is a useful screening test for IBD, a normal FC alone does not exclude IBD. Extending FC to include albumin or platelet count may improve sensitivity, specificity, PPV and NPV in diagnosing IBD. However, prospective studies are required to validate this conclusion.

Keywords: inflammatory bowel disease, fecal calprotectin, serum albumin, platelet count, pediatrics, diagnosis

\section{INTRODUCTION}

Inflammatory bowel disease (IBD) is a chronic inflammatory condition involving the gastrointestinal tract, encompassing Crohn's disease (CD), ulcerative colitis (UC) and IBDunclassified (IBD-U). The incidence of IBD in New Zealand across all ages is known to be high by international standards, notably in the Canterbury region $(1,2)$. While the cause of IBD remains 
unclear, there is a growing awareness that a combination of host genetics and environmental factors that include diet and gut bacteria is likely to have a role in disease development (3).

In New Zealand, clinical guidelines produced by the National Pediatric Gastroenterology Clinical Network recommended blood (at least the following: full blood count, erythrocyte sedimentation rate (ESR), C-reactive protein (CRP) and albumin) and fecal tests to screen for the presence of systemic inflammation and exclude any gastrointestinal infections for any children suspected of having IBD (4). Measurement of fecal calprotectin (FC) is included as one of the initial investigations. Calprotectin is a $36-\mathrm{kDa}$ heterodimer of the S100A8 and S100A9 proteins, which is released predominantly by neutrophils, and a lesser extent by monocytes and macrophages, in response to infection or inflammation $(5,6)$. Calprotectin found in feces is more specific to gastrointestinal inflammation than calprotectin found in other body fluids (7). Hence, FC has been found to be useful in screening purposes and distinguishing inflammatory from non-inflammatory gastrointestinal conditions such as irritable bowel syndrome (8).

The study hypothesized that combining FC with other standard blood tests improved the diagnosis of IBD compared to FC alone. This study aimed to explore various FC thresholds in the diagnosis of pediatric IBD, and to ascertain whether a combination of FC with other standard blood tests could improve the diagnostic utility.

\section{METHODS}

\section{Patient Selection}

Children and adolescents under 17 years of age who underwent colonoscopy at Christchurch Hospital, Canterbury, New Zealand between 1 January 2016 and 30 September 2018 (33 months) were retrospectively identified from the hospital database. The indications for endoscopy were either investigation of persistent symptoms, such as hematochezia, or to exclude IBD. The endoscopists were not blinded for the indication of investigation. Patients who had FC measured prior to their endoscopy investigation were included (Figure 1). These children were categorized into IBD or non-IBD groups. Diagnosis of IBD, inclusive of $\mathrm{CD}$, UC and IBD-U, was made based on the European Society of Pediatric Gastroenterology, Hepatology and Nutrition (ESPGHAN) Revised Porto criteria (9) and the Paris classification (10).

Each patient's medical record was accessed to document the patient's background, results of any fecal, blood, imaging and histology investigations, disease extent in those diagnosed with IBD and final diagnosis for those with non-IBD. Exclusion criteria included children with known IBD, evidence of recent gastrointestinal infection or recent administration of nonsteroid anti-inflammatory medications. Due to insufficient documentation of symptoms in the medical records, a symptoms variable was not included in the analysis.

This study was approved by the University of Otago Ethics Committee (Health). The full study protocol can be accessed by contacting the authors.

\section{Fecal Calprotectin Test}

Measurement of FC levels was performed by a central local laboratory, Canterbury Health Laboratories (CHL) using Calpro Calprotectin ELISA assay (Calpro AS, Norway), usually with some clinical information on the request form. Such clinical information was not available and not included in the analysis of this study. The assay reported the normal range of FC as $<50 \mu \mathrm{g} / \mathrm{g}$ and up to $500 \mu \mathrm{g} / \mathrm{g}$. Increments of $50 \mu \mathrm{g} / \mathrm{g}$ were used to explore the optimal threshold (up to a maximum threshold of $250 \mu \mathrm{g} / \mathrm{g}$ ) that best diagnosed IBD.

\section{Other Blood Tests}

Blood results, including low albumin, elevated platelet count, erythrocyte sedimentation rate (ESR) or C-reactive protein (CRP) were likewise categorized as normal or abnormal based on the reference ranges provided by the two laboratories (CHL and Canterbury SCL) that serve the local region. (Normal reference ranges for CHL: albumin $>1$ year- 8 years: $35-45 \mathrm{~g} / \mathrm{L},>8-15$ years: $37-47 \mathrm{~g} / \mathrm{L}$ and $>15$ years: $32-48 \mathrm{~g} / \mathrm{L}$, platelet count: $>1$ year-3 years: $150-500 \times 10^{9} / \mathrm{L},>3-7$ years: $150-475 \times 10^{9} / \mathrm{L}$, $>7-12$ years: $150-425 \times 10^{9} / \mathrm{L},>12$ years: $150-400 \times 10^{9} / \mathrm{L}$, CRP: $<5 \mathrm{mg} / \mathrm{L}$, high sensitive CRP: $<1.0 \mathrm{mg} / \mathrm{L}$ and ESR: 1$10 \mathrm{~mm} / \mathrm{h}$; Canterbury SCL: albumin 32-48 g/L, CRP: $<5 \mathrm{mg} / \mathrm{L}$, ESR: $1-10 \mathrm{~mm} / \mathrm{h}$, platelet count: $>1$ year- 3 years: $150-500 \times$ $10^{9} / \mathrm{L},>3-7$ years: $150-475 \times 10^{9} / \mathrm{L},>7-12$ years: $150-425 \times$ $10^{9} / \mathrm{L},>12$ years: $\left.150-400 \times 10^{9} / \mathrm{L}\right)$.

\section{Statistical Analysis}

Statistical analysis was performed using GraphPad Prism version 9.0.0 (86) macOS, Version 26.0 (GraphPad Software, California, USA) for descriptive analysis, sensitivity (the proportion of children with IBD that the test correctly identifies as positive, true positive), specificity (the proportion of children with nonIBD that the test correctly identifies as negative, true negative), positive predictive value, PPV (the probability of a patient having IBD when the test is positive) and negative predictive value, NPV (the probability of a patient not having IBD when the test is negative). When PPV was reported to be the highest value in diagnosing IBD, odds ratio (OR) was also provided. Each value was accompanied by $95 \%$ confident interval (CI) calculated using the Wilson-Brown method (for sensitivity, specificity, PPV and NPV) and Baptista-Pike method (for OR). A two-tailed $p<0.05$ was considered statistically significant.

Patients were identified by consecutive sampling based on the study period, which also determine the final sample size. Patients with missing data (e.g., blood results not available) were excluded from the analysis. In addition, results on missed IBD and colonoscopy not required were provided for each FC threshold alone or FC combined with standard blood results.

\section{RESULTS}

\section{Patient Backgrounds}

One hundred and twenty-eight children were potentially eligible participants (Figure 1). After excluding 26 children with previously known IBD, 102 children with mean age $( \pm$ standard deviation, SD) of $12.3 \pm 3.5$ years and 53 (52\%) 


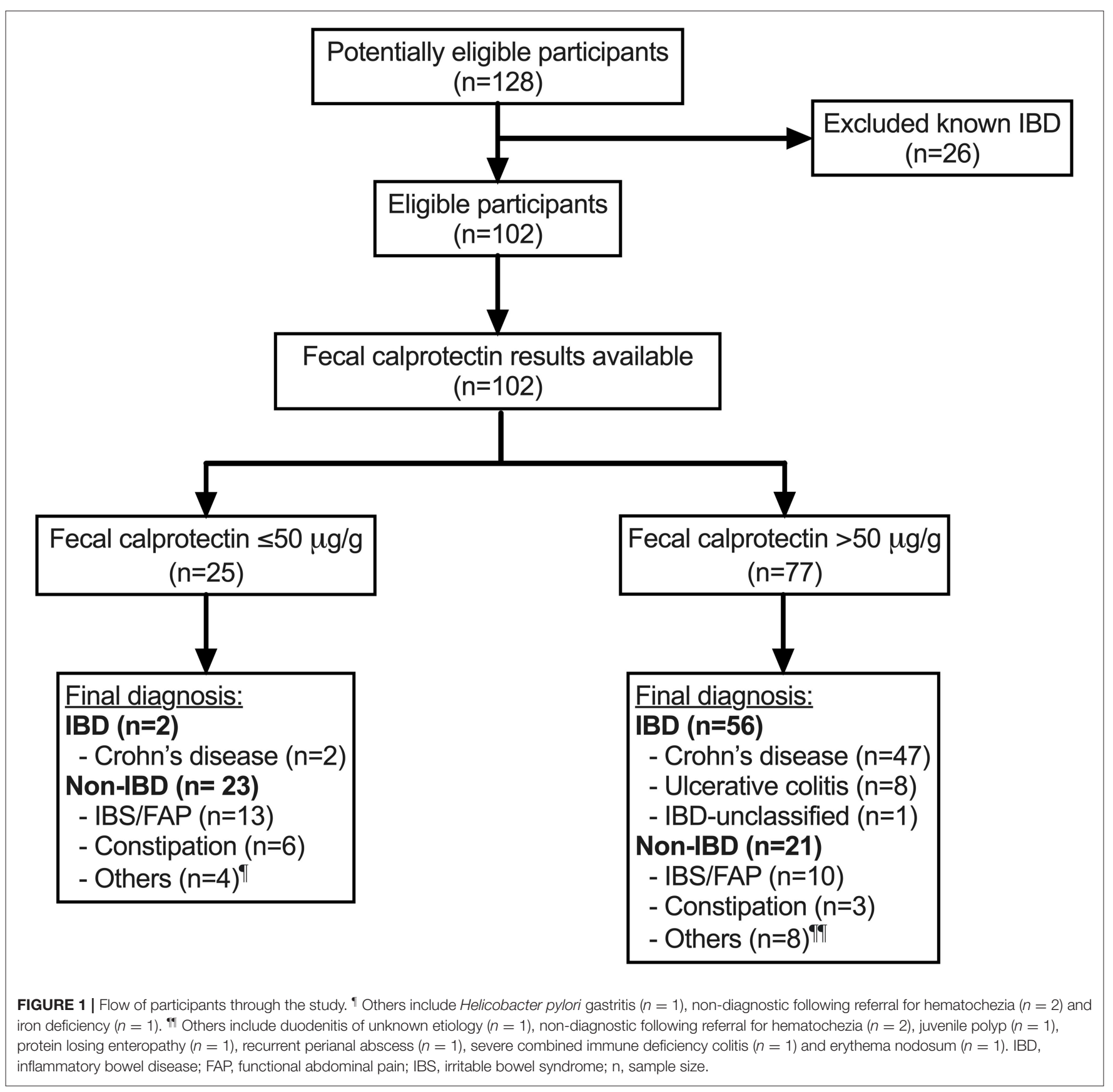

male were included in the analysis (Table 1). Of the 102 children, 58 (57\%) were newly diagnosed with IBD: 49 with $\mathrm{CD}$, eight with UC and one with IBD-U, and $44(43 \%)$ did not have IBD (non-IBD). At least half of the children without IBD were diagnosed with functional abdominal pain or irritable bowel syndrome. A quarter of the whole cohort were found to have $\mathrm{FC} \leq 50 \mu \mathrm{g} / \mathrm{g}$ (normal range) and the rest of the children had $\mathrm{FC}>50 \mu \mathrm{g} / \mathrm{g}$. Overall, the mean $( \pm$ $\mathrm{SD})$ duration between measurement of FC and endoscopy was $2.0 \pm 3.0$ months.

\section{Fecal Calprotectin (FC) Test}

Using the standard lab reference $(<50 \mu \mathrm{g} / \mathrm{g})$, FC provided a sensitivity of $96.6 \%$ (95\% CI $88.3-99.4 \%$ ), specificity of $52.3 \%$ (95\% CI $37.9-66.3 \%)$, PPV of $72.7 \%$ (95\% CI 61.9-81.4\%) and NPV of $92.0 \%$ (95\% CI 75.0-98.6\%) in diagnosing IBD (Table 2). Similarly, if the standard lab reference was applied as a screening test for the decision to undertake an endoscopy, 25 of 102 (25\%) endoscopies would not have been required. However, two children with IBD would have been missed. One of these two children was an 8-year old child with CD involving the duodenal 
TABLE 1 | Background characteristics of 102 children and adolescents diagnosed with and without inflammatory bowel disease (IBD).

\begin{tabular}{|c|c|c|c|}
\hline & $\begin{array}{c}\text { Total } \\
(n=102)\end{array}$ & $\begin{array}{c}\text { IBD } \\
(n=58)\end{array}$ & $\begin{array}{c}\text { Non-IBD } \\
(n=44)\end{array}$ \\
\hline $\begin{array}{l}\text { Age at diagnosis, mean } \pm \text { standard } \\
\text { deviation }\end{array}$ & $\begin{array}{c}12.3 \pm 3.5 \\
\text { years }\end{array}$ & $\begin{array}{c}12.3 \pm 3.1 \\
\text { years }\end{array}$ & $\begin{array}{l}12.2 \pm 4.0 \\
\text { years }\end{array}$ \\
\hline Male, n (\%) & $53(52)$ & $33(57)$ & $20(46)$ \\
\hline \multicolumn{4}{|l|}{ Ethnicity, n } \\
\hline \multicolumn{3}{|l|}{ European } & 43 \\
\hline Māori & 6 & 2 & 4 \\
\hline Other Asian & 3 & 1 & 2 \\
\hline Not specified & 6 & 3 & 3 \\
\hline IBD subtypes, n (\%) & $\mathrm{N} / \mathrm{A}$ & $58(57)$ & $\mathrm{N} / \mathrm{A}$ \\
\hline$\underline{\text { Crohn's disease }}^{\dagger}$ & & $49(85)$ & \\
\hline \multicolumn{4}{|l|}{ Age at diagnosis } \\
\hline 0 to $<10$ years $(\mathrm{A} 1 \mathrm{a})$ & & 10 & \\
\hline 10 to $<17$ years $(\mathrm{A} 1 \mathrm{~b})$ & & 39 & \\
\hline \multicolumn{4}{|l|}{ Location } \\
\hline $\begin{array}{l}\text { Distal third of ileum } \pm \text { cecal disease } \\
(\llcorner 1)\end{array}$ & & 6 & \\
\hline Colonic (L2) & & 12 & \\
\hline Ileocolonic (L3) & & 28 & \\
\hline $\begin{array}{l}\text { Upper disease proximal to ligament } \\
\text { of Trietz ( }(\mathrm{4a})\end{array}$ & & 17 & \\
\hline $\begin{array}{l}\text { Upper disease distal to ligament of } \\
\text { Trietz (L4b) }\end{array}$ & & 2 & \\
\hline $\begin{array}{l}\text { Upper disease to distal third of } \\
\text { ileum (L4ab) }\end{array}$ & & 7 & \\
\hline \multicolumn{4}{|l|}{ Behavior } \\
\hline $\begin{array}{l}\text { Non-stricturing and } \\
\text { non-penetrating (B1) }\end{array}$ & & 45 & \\
\hline Stricturing (B2) & & 2 & \\
\hline Penetrating (B3) & & 2 & \\
\hline $\begin{array}{l}\text { Both structuring and penetrating } \\
\text { disease (B2B3) }\end{array}$ & & 0 & \\
\hline Perianal disease (p) & & 11 & \\
\hline$\underline{\text { Ulcerative colitis }}^{\dagger}$ & & $8(14)$ & \\
\hline \multicolumn{4}{|l|}{ Extent } \\
\hline Proctitis (E1) & & 0 & \\
\hline Left-sided colitis (E2) & & 2 & \\
\hline Extensive colitis (E3) & & 1 & \\
\hline Pancolitis (E4) & & 5 & \\
\hline \multicolumn{4}{|l|}{ Severity } \\
\hline Never severe (SO) & & 8 & \\
\hline Ever severe (S1) & & 0 & \\
\hline IBD-unclassified & & $1(2)$ & \\
\hline Non-IBD, n (\%) & N/A & N/A & $44(43)$ \\
\hline $\begin{array}{l}\text { Functional abdominal pain/irritable } \\
\text { bowel syndrome }\end{array}$ & & & 23 \\
\hline Constipation & & & 9 \\
\hline Juvenile polyp & & & 1 \\
\hline Others $^{\ddagger}$ & & & 11 \\
\hline \multicolumn{4}{|c|}{ Patients with various fecal calprotectin thresholds, n (\%) } \\
\hline$\leq 50 \mu \mathrm{g} / \mathrm{g}^{\S}$ & $25(25)$ & $2(3)$ & $23(52)$ \\
\hline
\end{tabular}

(Continued)
TABLE 1 | Continued

\begin{tabular}{|c|c|c|c|}
\hline & $\begin{array}{c}\text { Total } \\
(n=102)\end{array}$ & $\begin{array}{c}\text { IBD } \\
(n=58)\end{array}$ & $\begin{array}{l}\text { Non-IBD } \\
(n=44)\end{array}$ \\
\hline$\geq 50 \mu \mathrm{g} / \mathrm{g}$ & $77(76)$ & $56(97)$ & $21(48)$ \\
\hline$\geq 100 \mu \mathrm{g} / \mathrm{g}$ & $72(71)$ & $54(93)$ & $18(41)$ \\
\hline$\geq 150 \mu \mathrm{g} / \mathrm{g}$ & $69(68)$ & $53(91)$ & $16(36)$ \\
\hline$\geq 200 \mu \mathrm{g} / \mathrm{g}$ & $66(65)$ & $51(88)$ & $15(34)$ \\
\hline$\geq 250 \mu \mathrm{g} / \mathrm{g}$ & $65(64)$ & $50(86)$ & $15(34)$ \\
\hline \multicolumn{4}{|l|}{ Blood tests, n (\%) } \\
\hline Albumin & $93(91)$ & $54(93)$ & $39(89)$ \\
\hline Low albumin ${ }^{\dagger \dagger}$ & $34(37)$ & $33(61)$ & $1(3)$ \\
\hline Platelet count & $101(99)$ & $57(56)$ & $44(44)$ \\
\hline Elevated platelet count ${ }^{\dagger \dagger}$ & $28(28)$ & $25(44)$ & $3(7)$ \\
\hline Erythrocyte sedimentation rate (ESR) & $76(75)$ & $47(62)$ & $29(38)$ \\
\hline Elevated ESR ${ }^{\dagger \dagger}$ & $41(54)$ & $36(77)$ & $5(17)$ \\
\hline C-reactive protein (CRP) & $101(99)$ & $57(56)$ & $44(44)$ \\
\hline Elevated CRP'† & $41(41)$ & $34(60)$ & $7(16)$ \\
\hline $\begin{array}{l}\text { Duration between fecal } \\
\text { calprotectin and endoscopy, mean } \\
\pm \text { standard deviation }\end{array}$ & $\begin{array}{c}2.0 \pm 3.0 \\
\text { months }\end{array}$ & $\begin{array}{c}0.9 \pm 1.3 \\
\text { months }\end{array}$ & $\begin{array}{c}3.5 \pm 3.8 \\
\text { months }\end{array}$ \\
\hline
\end{tabular}

\$Standard laboratory threshold.

${ }^{\dagger}$ Based on the Paris classification (10).

${ }^{\dagger \dagger}$ Percentage was calculated based on the available test results.

$\neq$ Others: iron deficiency $(n=1)$, Helicobacter pylori gastritis $(n=1)$, duodenitis of unknown etiology $(n=1)$, protein losing enteropathy $(n=1)$, severe combined immune deficiency colitis $(n=1)$, recurrent perianal abscess $(n=1)$, erythema nodosum $(n=1)$, and non-diagnostic following referral for hematochezia $(n=4)$.

$I B D$, inflammatory bowel disease; N/A, not applicable.

and ileocolonic regions, and the other was a 3-year old child with orofacial granulomatosis and perianal CD (non-luminal disease).

Using various FC thresholds $(50,100,150,200$, and $250 \mu \mathrm{g} / \mathrm{g}$ ), a threshold of $200 \mu \mathrm{g} / \mathrm{g}$ was found to provide the highest PPV for the diagnosis of IBD $(77.3 \%, 95 \%$ CI $65.8-85.7 \%)$ and OR 14.1 (95\% CI 5.0-34.5, $p<0.0001$ ) likelihood of having IBD (Table 2). In addition, the specificity of FC improved with higher thresholds, but did not improve beyond $200 \mu \mathrm{g} / \mathrm{g}$. Similarly, a threshold of $200 \mu \mathrm{g} / \mathrm{g}$ was found to provide the highest PPV for the diagnosis of $\mathrm{CD}(73.7 \%, 95 \% \mathrm{CI} 61.1-83.4 \%)$; these children were 11.6 times (95\% CI 4.1-28.8, $p<0.0001$ ) more likely to have IBD. The specificity of FC improved with higher thresholds, but not beyond $200 \mu \mathrm{g} / \mathrm{g}$ (maximum specificity of $65.9 \%, 95 \% \mathrm{CI}$ 51.1-78.1\%) (Table 3).

\section{Fecal Calprotectin or Abnormal Blood Tests}

Utilizing various FC thresholds or abnormal blood results (albumin, platelet count, ESR and CRP) improved the sensitivity and NPV in diagnosing IBD. Employing FC $>50 \mu \mathrm{g} / \mathrm{g}$ or having an elevated platelet count increased sensitivity from $96.6 \%(95 \%$ CI 88.3-99.4\%) to 98.3\% (95\% CI 90.7-99.1\%) in diagnosing IBD, compared to $\mathrm{FC}>50 \mu \mathrm{g} / \mathrm{g}$ alone (Tables 2,4 ). If these criteria were used for the endoscopy investigation decision, 23 of 102 (23\%) endoscopies would not have been required and one patient with IBD would have been missed. The calculation of NPV in 
TABLE 2 | Sensitivity, specificity, positive predictive values (PPV), negative predictive values (NPV), missed inflammatory bowel disease (IBD) diagnosis and number of endoscopies not required when various fecal calprotectin thresholds were used in diagnosing IBD.

\begin{tabular}{|c|c|c|c|c|c|c|c|}
\hline $\begin{array}{l}\text { Fecal } \\
\text { calprotectin } \\
\text { threshold }\end{array}$ & $n$ & $\begin{array}{c}\text { Sensitivity, \% } \\
\text { (95\% Cl) }\end{array}$ & $\begin{array}{l}\text { Specificity, \% } \\
\text { (95\% Cl) }\end{array}$ & PPV, \% (95\% Cl) & NPV, \% (95\% Cl) & $\begin{array}{c}\text { Missed IBD, n } \\
(\%)\end{array}$ & $\begin{array}{l}\text { Endoscopy not } \\
\text { required, n (\%) }\end{array}$ \\
\hline$>50 \mu \mathrm{g} / \mathrm{g}$ & 102 & 96.6 (88.3-99.4) & 52.3 (37.9-66.3) & 72.7 (61.9-81.4) & $92.0(75.0-98.6)$ & $2(2)$ & $25(25)$ \\
\hline$>100 \mu \mathrm{g} / \mathrm{g}$ & 102 & 93.1 (83.6-97.3) & $59.1(44.4-72.3)$ & 75.0 (63.9-83.6) & 86.7 (70.3-94.7) & $4(4)$ & $30(29)$ \\
\hline$>150 \mu \mathrm{g} / \mathrm{g}$ & 102 & $91.4(81.4-96.3)$ & $63.6(48.9-76.2)$ & 76.8 (65.6-84.2) & $84.8(69.1-93.4)$ & $5(5)$ & $33(32)$ \\
\hline$>200 \mu \mathrm{g} / \mathrm{g}$ & 102 & $87.9(77.1-94.0)$ & $65.9(51.1-78.1)$ & $77.3^{\prime \prime}(65.8-85.7)$ & 80.6 (65.0-90.3) & $7(7)$ & $36(35)$ \\
\hline$>250 \mu \mathrm{g} / \mathrm{g}$ & 102 & $86.2(75.1-92.8)$ & $65.9(51.1-78.1)$ & 76.9 (65.4-85.5) & 78.4 (62.8-88.6) & $8(8)$ & $37(36)$ \\
\hline
\end{tabular}

II Odds ratio was 14.1 (95\% Cl 5.0-34.5), $p<0.0001$ likelihood of having IBD.

$\mathrm{Cl}$, confident interval; $n$, sample size.

TABLE 3 | Sensitivity, specificity, positive predictive values (PPV), negative predictive values (NPV), missed Crohn's disease (CD) diagnosis, and number of endoscopies not required when various fecal calprotectin thresholds were used in diagnosing CD.

\begin{tabular}{|c|c|c|c|c|c|c|c|}
\hline $\begin{array}{l}\text { Fecal } \\
\text { calprotectin } \\
\text { threshold }\end{array}$ & $n$ & $\begin{array}{c}\text { Sensitivity, \% } \\
\text { (95\% Cl) }\end{array}$ & $\begin{array}{l}\text { Specificity, \% } \\
\text { (95\% Cl) }\end{array}$ & PPV, \% (95\% CI) & NPV, \% (95\% Cl) & $\begin{array}{c}\text { Missed IBD, n } \\
(\%)\end{array}$ & $\begin{array}{l}\text { Endoscopy not } \\
\text { required, n (\%) }\end{array}$ \\
\hline$>50 \mu \mathrm{g} / \mathrm{g}$ & 93 & 95.9 (86.3-99.3) & 52.3 (37.9-66.3) & $69.1(57.4-78.8)$ & 92.0 (75.0-98.6) & $2(2)$ & $25(27)$ \\
\hline$>100 \mu \mathrm{g} / \mathrm{g}$ & 93 & 91.8 (80.8-98.8) & 59.1 (44.4-72.3) & $71.4(59.3-81.1)$ & 86.7 (80.3-94.7) & $4(4)$ & $30(32)$ \\
\hline$>150 \mu \mathrm{g} / \mathrm{g}$ & 93 & 89.8 (78.2-95.6) & $63.6(48.9-76.2)$ & 73.3 (61.0-72.9) & $84.8(69.1-93.4)$ & $5(5)$ & 33 (35) \\
\hline$>200 \mu \mathrm{g} / \mathrm{g}$ & 93 & 85.7 (73.3-92.9) & $65.9(51.1-78.1)$ & $73.7^{\prime \prime}(61.1-83.4)$ & 80.6 (65.0-90.3) & $7(8)$ & $36(39)$ \\
\hline$>250 \mu \mathrm{g} / \mathrm{g}$ & 93 & 83.7 (71.0-91.5) & $65.9(51.1-78.1)$ & 73.2 (60.4-83.0) & 78.4 (62.8-88.6) & $8(9)$ & $37(40)$ \\
\hline
\end{tabular}

II Odds ratio was 11.6 (95\% Cl 4.1-28.8), $p<0.0001$ likelihood of having IBD.

$\mathrm{Cl}$, confident interval; $n$, sample size.

diagnosing IBD was found to be the highest at $96.0 \%$ when the FC threshold was set at $200 \mu \mathrm{g} / \mathrm{g}$ or low albumin was present (i.e., if one has FC $<200 \mu \mathrm{g} / \mathrm{g}$ and normal albumin level, there is $96.0 \%$ (95\% CI $80.5-99.8 \%$ ) probability the child does not have IBD) (Supplementary Table 1).

Sensitivity, specificity, PPV and NPV in diagnosing IBD were also analyzed using various FC cut-offs or having low albumin, elevated ESR and CRP (Supplementary Tables 1-3). None of these combinations improved the sensitivity or NPV better than a high platelet count except for low albumin, which was comparable. Furthermore, evaluating various FC thresholds or having either low albumin or high platelets did not improve sensitivity or NPV further in diagnosing IBD (Supplementary Table 4).

\section{Fecal Calprotectin and Abnormal Blood Tests}

The specificity and PPV in diagnosing IBD could be further improved when FC of various thresholds was combined with either low albumin or high platelet count. Specificities and PPVs were $97.4 \%$ (95\% CI 86.8-99.9\%) and 97.3\% (95\% CI 86.2-99.9\%) for $\mathrm{FC}>50 \mu \mathrm{g} / \mathrm{g}, 100 \%(95 \% \mathrm{CI} 90.1-100 \%)$ and $100 \%(95 \%$ CI $90.1-100 \%$ ) for $\mathrm{FC}>100,150,200$, or $250 \mu \mathrm{g} / \mathrm{g}$, respectively (Table 5).

\section{DISCUSSION}

The current study found the FC standard lab reference $(<50 \mu \mathrm{g} / \mathrm{g})$ provided an excellent sensitivity of $96.6 \%(95 \% \mathrm{CI}$ $88.3-99.4 \%)$ but poor specificity $(52.3 \%, 95 \%$ CI $37.9-66.3 \%)$ in diagnosing IBD in this group of children. Two children with IBD in this group were found to have normal FC levels. In children who had FC $>50 \mu \mathrm{g} / \mathrm{g}$, there was $72.7 \%$ (95\% CI $61.9-81.4 \%$ ) probability of being diagnosed with IBD (PPV). PPV marginally improved to $77.3 \%$ (95\% CI 65.8-85.7\%) if the FC threshold was increased to $200 \mu \mathrm{g} / \mathrm{g}$. In addition, sensitivity in diagnosing IBD could be improved further (increasing from 96.6 to $98.3 \%$ ) if the criteria included either a FC threshold of $>50 \mu \mathrm{g} / \mathrm{g}$ or an elevated platelet count. On the other hand, the combination of a FC threshold $>50 \mu \mathrm{g} / \mathrm{g}$ with either low serum albumin or high platelet count increased PPV in diagnosing IBD from 72.7 to $97.3 \%$ and $100 \%$ if $\mathrm{FC}>100 \mu \mathrm{g} / \mathrm{g}$ threshold was used.

FC as a stand-alone test is a highly sensitive but not specific test in identifying pediatric IBD. Systemic review and metaanalysis studies have reported FC sensitivity ranging from 0.92 to 0.99 and specificity from 0.65 to 0.76 in the utility of diagnosing pediatric IBD (11-14). The sensitivity of FC (using the standard lab threshold) reported in the current study is consistent (96.6\%) with the current literature but marginally lower specificity (52.3\%). Furthermore, FC is found to be a far superior test than standard blood tests (albumin, ESR, CRP, 
TABLE 4 | Sensitivity, specificity, positive predictive values (PPV), negative predictive values (NPV), missed inflammatory bowel disease (IBD) diagnosis and number of endoscopies not required when various fecal calprotectin thresholds or high platelet count were used in diagnosing IBD.

\begin{tabular}{|c|c|c|c|c|c|c|c|}
\hline $\begin{array}{l}\text { Fecal } \\
\text { calprotectin } \\
\text { threshold (or } \\
\text { high platelet } \\
\text { count) }\end{array}$ & $n$ & $\begin{array}{l}\text { Sensitivity, \% } \\
\text { (95\% Cl) }\end{array}$ & $\begin{array}{l}\text { Specificity, \% } \\
\text { (95\% Cl) }\end{array}$ & PPV, \% (95\% Cl) & NPV, \% (95\% Cl) & $\begin{array}{c}\text { Missed IBD, n } \\
(\%)\end{array}$ & $\begin{array}{l}\text { Endoscopy not } \\
\text { required, n (\%) }\end{array}$ \\
\hline$>50 \mu \mathrm{g} / \mathrm{g}$ & 101 & 98.3 (90.7-99.1) & $50.0(35.8-64.2)$ & $71.8(61.0-80.6)$ & 95.7 (79.0-99.8) & $1(1)$ & $23(23)$ \\
\hline$>100 \mu \mathrm{g} / \mathrm{g}$ & 101 & 96.5 (88.1-99.4) & $54.5(40.1-68.3)$ & 73.3 (62.4-82.0) & 92.3 (75.9-98.6) & $2(2)$ & $26(26)$ \\
\hline$>150 \mu \mathrm{g} / \mathrm{g}$ & 101 & 96.5 (88.1-99.4) & $56.8(42.2-70.3)$ & 74.7 (63.8-82.9) & 92.6 (76.6-98.7) & $2(2)$ & $27(27)$ \\
\hline$>200 \mu \mathrm{g} / \mathrm{g}$ & 101 & 94.7 (85.6-98.6) & $59.1(44.4-72.3)$ & $75.0^{\prime \prime}(63.9-83.6)$ & 89.7 (73.6-96.4) & $3(3)$ & $29(29)$ \\
\hline$>250 \mu \mathrm{g} / \mathrm{g}$ & 101 & $93.0(83.3-97.2)$ & $59.1(44.4-72.3)$ & 74.7 (63.5-83.3) & 86.7 (70.3-94.7) & $4(4)$ & $30(30)$ \\
\hline
\end{tabular}

II Odds ratio was 26.0 (95\% Cl 7.1-85.9), $p<0.0001$ likelihood of having IBD.

$\mathrm{Cl}$, confident interval; $n$, sample size.

TABLE 5 | Sensitivity, specificity, positive predictive values (PPV), negative predictive values (NPV) when combined various fecal calprotectin thresholds with either low serum albumin or high platelet count were used in diagnosing IBD.

\begin{tabular}{|c|c|c|c|c|c|}
\hline $\begin{array}{l}\text { Fecal calprotectin threshold and (low } \\
\text { albumin or high platelet count) }\end{array}$ & $n$ & $\begin{array}{l}\text { Sensitivity, \% } \\
\quad(95 \% \mathrm{Cl})\end{array}$ & $\begin{array}{l}\text { Specificity, \% } \\
\text { (95\% Cl) }\end{array}$ & PPV, \% (95\% Cl) & NPV, $\%(95 \%$ Cl) \\
\hline$>50 \mu \mathrm{g} / \mathrm{g}$ & 92 & $67.9(54.5-78.9)$ & 97.4 (86.8-99.9) & 97.3 (86.2-99.9) & $69.1(56.0-79.7)$ \\
\hline$>100 \mu \mathrm{g} / \mathrm{g}$ & 92 & $66.0(52.6-77.3)$ & $100(91.0-100)$ & $100^{\prime \prime}(90.1-100)$ & $68.4(55.5-79.0)$ \\
\hline$>150 \mu \mathrm{g} / \mathrm{g}$ & 92 & $64.2(50.7-75.7)$ & 100 (91.0-100) & 100 (89.9-100) & $67.2(54.4-77.9)$ \\
\hline$>200 \mu \mathrm{g} / \mathrm{g}$ & 92 & $60.4(46.9-72.4)$ & 100 (91.0-100) & 100 (89.3-100) & $65.0(52.4-75.8)$ \\
\hline$>250 \mu \mathrm{g} / \mathrm{g}$ & 92 & $60.4(46.9-72.4)$ & 100 (91.0-100) & 100 (89.3-100) & $65.2(52.4-75.8)$ \\
\hline
\end{tabular}

II Odds ratio was infinity (95\% Cl 18.4-infinity), $p<0.0001$ likelihood of having IBD.

$\mathrm{Cl}$, confident interval; $n$, sample size.

hemoglobin, white cell count or platelet count) in diagnosing IBD among children suspected of having IBD (15).

A number of studies have evaluated the usefulness of FC in the primary-care setting where IBD can be safely excluded and avoid unnecessary referrals or endoscopy (16-18). The most recent study by Walker et al. (18) demonstrated that a FC $>100 \mu \mathrm{g} / \mathrm{g}$ is able to fully discriminate (100\% sensitivity) children with IBD from those who do not have IBD in a primarycare setting. Nevertheless, in the present study (in a tertiary hospital setting) two children with IBD had normal FC results $(<50 \mu \mathrm{g} / \mathrm{g})$. One was an 8-year old child diagnosed with $\mathrm{CD}$ involving the duodenal and ileocolonic regions (non-stricturing). This child also found to have concurrent elevated inflammatory markers (platelet count, ESR and CRP). The other case was a 3-year old child with orofacial granulomatosis and perianal CD without any luminal involvement when FC was measured. This child also had normal inflammatory markers as part of the initial workup. However, when the child subsequently developed colonic disease, the FC was noted to be elevated. Two earlier studies also reported a small number of children with normal FC levels at the time of diagnosis of IBD $(19,20)$; the ESPGHAN GROWTH CD study (20) reported normal FC values in three of 60 children with newly diagnosed CD and a Scottish study showed this in two of 46 children with IBD (19). Hence, the clinical decision to refer to a gastroenterologist or proceed with endoscopy should not solely rely on FC measurement alone, but should take consideration of the clinical features and results of other available investigations.

Although it is uncommon for children with IBD to have a normal FC, inflammatory markers such as ESR or CRP are commonly elevated. The study by Quail et al. (19) reported two of 46 children with IBD had normal FC, but all children had at least one abnormal blood test and/or elevated FC at diagnosis. The current study analyzed the diagnostic sensitivity in IBD (avoiding missing true positive) using either FC (various thresholds) or abnormal inflammatory markers (low albumin, elevated platelets, CRP or ESR). When FC level was elevated ( $\geq 50 \mu \mathrm{g} / \mathrm{g}$ ) or platelet count elevated, sensitivity in the diagnosis of IBD increased from 96.6 to $98.3 \%$. If such criteria ( $\mathrm{FC} \geq 50 \mu \mathrm{g} / \mathrm{g}$ or elevated platelet count) were applied for endoscopy investigation decision, 23 children would not require an endoscopy assessment with one child with IBD (a child with non-luminal CD involvement). Interpretation of this analysis may potentially be biased toward $\mathrm{CD}$ as the majority (85\%) of children in the current cohort were diagnosed with $\mathrm{CD}$. A recent prospective study evaluated four diagnostic strategies (symptoms alone, symptoms plus blood markers (elevated CRP or anemia), symptoms plus FC $(\geq 250 \mu \mathrm{g} / \mathrm{g})$ and symptoms plus blood markers plus FC) to predict IBD diagnosis in 193 children aged between 6 and 18 years with persistent non-bloody diarrhea and abdominal pain (21). This study found the combination of symptoms with blood and stool markers was the best strategy to predict IBD in these 
children, with a superior area under the curve (AUC) of 0.997 compared to the other strategies (21). Nevertheless, this strategy is not applicable to children presenting with rectal bleeding or perianal disease.

Similarly, improving IBD diagnostic accuracy by combining FC with symptoms suggestive of IBD has also been evaluated $(22,23)$. A meta-analysis study of eight studies $(n=1,120)$ found FC to add the most diagnostic value to symptoms by reducing the children with IBD incorrectly classified as low risk of IBD from 16 to $9 \%(22)$. While in the primary care setting, a prospective study involving 90 children with chronic gastrointestinal symptoms found the most optimal strategy to identify patients of being high risk for IBD was to add FC to alarm symptoms (such as hematochezia, first-degree family history of IBD, involuntary weight loss, growth failure, extra-intestinal features or perianal lesions), which significantly increased the AUC compared to alarm symptoms alone ( 0.80 and 0.97 , respectively) (23). The retrospective nature of the current study limited the ability to ascertain the presenting symptoms for all children: consequently, this was not able to be evaluated.

In most locations, access to endoscopy is limited and clinicians are required to prioritize patients accordingly. In order to assist such prediction (establishing which patients truly have IBD), the current study and two other reports have evaluated FC results in combination with various tests $(24,25)$. All studies found combining FC with another test to be superior to FC alone. The current study found that combining FC (>50 $\mu \mathrm{g} / \mathrm{g})$ with either low serum albumin or high platelet count increased PPV in diagnosing IBD from 72.7 to $97.3 \%$, compared to FC alone. This suggests that patients with such test results should be prioritized for endoscopy. The study by Daniluk et al. (24) evaluated 128 children with chronic gastrointestinal symptoms with FC $>150 \mu \mathrm{g} / \mathrm{g}$ and found that FC combined with ESR, CRP or albumin provided the best PPV (82.1\% and AUC 0.92; $P=0.04)$ in diagnosing IBD. Similarly, another study that evaluated 77 children with chronic gastrointestinal symptoms found FC (>200 $\mu \mathrm{g} / \mathrm{g}$ ) and intestinal ultrasound (US) gave PPV of $100 \%$ in diagnosing IBD (25). All these studies were analyzed retrospectively and prospective studies are required to validate this further.

The current study was limited by the retrospective study design, meaning that the medical team, pathologists or patients were not blinded and that not all subjects had a complete series of blood tests. There was a variable period of time between the FC testing and the endoscopy assessment consequent to endoscopy waiting times. It would be ideal for the interval between FC testing and endoscopy assessment to be as short as possible, allowing for FC results to more closely reflect the mucosal pathology. The FC results analyzed by incremental thresholds were treated as a dichotomous variable as the laboratory did not perform further dilution for any results beyond $500 \mu \mathrm{g} / \mathrm{g}$, which limits the calculation of optimal FC threshold using receiver operating characteristic curve analysis that would best distinguish IBD from non-IBD in this cohort of patients. Finally, this was a relatively small sample size with most of the children diagnosed with IBD classified as CD, which may have influenced the utility of the tests. However, each of the children was seen and investigated within the same pediatric unit.

In conclusion, FC alone is a useful screening test for IBD. However, a normal FC alone does not exclude IBD. The approach to combine FC with serum albumin or platelet count may improve sensitivity, specificity, PPV and NPV in diagnosing IBD. Furthermore, prospective studies are required to validate this conclusion.

\section{DATA AVAILABILITY STATEMENT}

The raw data supporting the conclusions of this article will be made available by the authors, without undue reservation.

\section{ETHICS STATEMENT}

The studies involving human participants were reviewed and approved by The University of Otago Ethics Committee (Health). Written informed consent for participation was not provided by the participants' legal guardians/next of kin because: This is a retrospective study and has no contact with human subjects. All data obtained from hospital or lab records.

\section{AUTHOR CONTRIBUTIONS}

$\mathrm{SSCH}$ was involved in study design, data entry, analyzed and interpreted the data, and wrote the initial draft of the manuscript. MR was involved in study design and data entry. $\mathrm{JK}$ was involved in study conception and supervision. AD was involved in study conception and design, analysis and interpretation of data arising, and supervision. All authors were involved in the critical review of the manuscript and all have approved and are accountable for the final version of the manuscript.

\section{FUNDING}

Freemasons New Zealand supports SSCH via the Freemasons Pediatric Postgraduate Scholarship.

\section{ACKNOWLEDGMENTS}

We would like to acknowledge Freemasons New Zealand for their support of SSCH via the Freemasons Pediatric Postgraduate Scholarship. We also thank Prof Chris Frampton for his statistical advice.

\section{SUPPLEMENTARY MATERIAL}

The Supplementary Material for this article can be found online at: https://www.frontiersin.org/articles/10.3389/fped. 2020.609279/full\#supplementary-material 


\section{REFERENCES}

1. Lopez RN, Evans HM, Appleton L, Bishop J, Chin S, Mouat S, et al. Point prevalence of pediatric inflammatory bowel disease in New Zealand in 2015: initial results from the PINZ study. Inflamm Bowel Dis. (2017) 23:141824. doi: 10.1097/MIB.0000000000001138

2. Su HY, Gupta V, Day AS, Gearry RB. Rising incidence of inflammatory bowel disease in Canterbury, New Zealand. Inflamm Bowel Dis. (2016) 22:223844. doi: 10.1097/MIB.0000000000000829

3. Khor B, Gardet A, Xavier RJ. Genetics and pathogenesis of inflammatory bowel disease. Nature. (2011) 474:307-17. doi: 10.1038/nature10209

4. Day AS. Management of Inflammatory Bowel Disease in Children and Adolescents in New Zealand - A Clinical Guideline. (2014). Available online at: https://media.starship.org.nz/inflammatory-bowel-disease--management-guideline/nz_ibd_clinical_guideline_aug_2015.pdf (accessed September 01, 2020).

5. Brandtzaeg P, Dale I, Fagerhol MK. Distribution of a formalin-resistant myelomonocytic antigen (L1) in human tissues. I. Comparison with other leukocyte markers by paired immunofluorescence and immunoenzyme staining. Am J Clin Pathol. (1987) 87:681-99. doi: 10.1093/ajcp/87.6.681

6. Johne B, Fagerhol MK, Lyberg T, Prydz H, Brandtzaeg P, Naess-Andresen $\mathrm{CF}$, et al. Functional and clinical aspects of the myelomonocyte protein calprotectin. Mol Pathol. (1997) 50:113-23. doi: 10.1136/mp.50.3.113

7. Pathirana WGW, Chubb SP, Gillett MJ, Vasikaran SD. Faecal calprotectin. Clin Biochem Rev. (2018) 39:77-90.

8. Ricciuto A, Griffiths AM. Clinical value of fecal calprotectin. Crit Rev Clin Lab Sci. (2019) 56:307-20. doi: 10.1080/10408363.2019.1619159

9. Levine A, Koletzko S, Turner D, Escher JC, Cucchiara S, de Ridder L, et al. ESPGHAN revised porto criteria for the diagnosis of inflammatory bowel disease in children and adolescents. J Pediatr Gastroenterol Nutr. (2014) 58:795-806. doi: 10.1097/MPG.0000000000000239

10. Levine A, Griffiths A, Markowitz J, Wilson DC, Turner D, Russell RK, et al. Pediatric modification of the Montreal classification for inflammatory bowel disease: the Paris classification. Inflamm Bowel Dis. (2011) 17:131421. doi: $10.1002 /$ ibd. 21493

11. Holtman GA, Lisman-van Leeuwen Y, Reitsma JB, Berger MY. Noninvasive tests for inflammatory bowel disease: a meta-analysis. Pediatrics. (2016) 137:111. doi: 10.1542/peds.2015-2126

12. Henderson P, Anderson NH, Wilson DC. The diagnostic accuracy of fecal calprotectin during the investigation of suspected pediatric inflammatory bowel disease: a systematic review and meta-analysis. Am J Gastroenterol. (2014) 109:637-45. doi: 10.1038/ajg.2013.131

13. Degraeuwe PL, Beld MP, Ashorn M, Canani RB, Day AS, Diamanti A, et al. Faecal calprotectin in suspected paediatric inflammatory bowel disease. J Pediatr Gastroenterol Nutr. (2015) 60:339-46. doi: 10.1097/MPG.0000000000000615

14. van Rheenen PF, van de Vijver E, Fidler V. Faecal calprotectin for screening of patients with suspected inflammatory bowel disease: diagnostic meta-analysis. BMJ. (2010) 341:c3369. doi: 10.1136/bmj.c3369

15. Henderson P, Casey A, Lawrence SJ, Kennedy NA, Kingstone K, Rogers P, et al. The diagnostic accuracy of fecal calprotectin during the investigation of suspected pediatric inflammatory bowel disease. Am J Gastroenterol. (2012) 107:941-9. doi: 10.1038/ajg.2012.33
16. Holtman GA, Lisman-van Leeuwen Y, Kollen BJ, Norbruis OF, Escher JC, Kindermann A, et al. Diagnostic accuracy of fecal calprotectin for pediatric inflammatory bowel disease in primary care: a prospective cohort study. Ann Fam Med. (2016) 14:437-45. doi: 10.1370/afm.1949

17. Ramraj R, Garcia A, Mosen D, Waiwaiole L, Smith N. Utility of fecal calprotectin in evaluation of chronic gastrointestinal symptoms in primary care. Clin Pediatr. (2018) 57:1058-63. doi: 10.1177/0009922817744607

18. Walker GJ, Chanchlani N, Thomas A, Lin S, Moore L, Heerasing NM, et al. Primary care faecal calprotectin testing in children with suspected inflammatory bowel disease: a diagnostic accuracy study. Arch Dis Child. (2020) 105:957-63. doi: 10.1136/archdischild-2019-317823

19. Quail MA, Russell RK, Van Limbergen JE, Rogers P, Drummond HE, Wilson DC, et al. Fecal calprotectin complements routine laboratory investigations in diagnosing childhood inflammatory bowel disease. Inflamm Bowel Dis. (2009) 15:756-9. doi: 10.1002/ibd.20820

20. Shaoul R, Sladek M, Turner D, Paeregaard A, Veres G, Wauters GV, et al. Limitations of fecal calprotectin at diagnosis in untreated pediatric Crohn's disease. Inflamm Bowel Dis. (2012) 18:1493-7. doi: 10.1002/ibd. 21875

21. Van de Vijver E, Heida A, Ioannou S, Van Biervliet S, Hummel $\mathrm{T}$, Yuksel $\mathrm{Z}$, et al. Test strategies to predict inflammatory bowel disease among children with nonbloody diarrhea. Pediatrics. (2020) 146:e20192235. doi: 10.1542/peds.2019-2235

22. Holtman GA, Lisman-van Leeuwen Y, Day AS, Fagerberg UL, Henderson $\mathrm{P}$, Leach ST, et al. Use of laboratory markers in addition to symptoms for diagnosis of inflammatory bowel disease in children: a metaanalysis of individual patient data. JAMA Pediatr. (2017) 171:98491. doi: 10.1001/jamapediatrics.2017.1736

23. Holtman GA, Lisman-van Leeuwen Y, Kollen BJ, Norbruis OF, Escher JC, Walhout LC, et al. Diagnostic test strategies in children at increased risk of inflammatory bowel disease in primary care. PLoS ONE. (2017) 12:e0189111. doi: 10.1371/journal.pone.0189111

24. Daniluk U, Daniluk J, Krasnodebska M, Lotowska JM, Sobaniec-Lotowska ME, Lebensztejn DM. The combination of fecal calprotectin with ESR, CRP and albumin discriminates more accurately children with Crohn's disease. Adv Med Sci. (2019) 64:9-14. doi: 10.1016/j.advms.2018. 08.001

25. Dilillo D, Zuccotti GV, Galli E, Meneghin F, Dell'Era A, Penagini $\mathrm{F}$, et al. Noninvasive testing in the management of children with suspected inflammatory bowel disease. Scand J Gastroenterol. (2019) 54:58691. doi: 10.1080/00365521.2019.1604799

Conflict of Interest: The authors declare that the research was conducted in the absence of any commercial or financial relationships that could be construed as a potential conflict of interest.

Copyright (c) 2021 Ho, Ross, Keenan and Day. This is an open-access article distributed under the terms of the Creative Commons Attribution License (CC BY). The use, distribution or reproduction in other forums is permitted, provided the original author(s) and the copyright owner(s) are credited and that the original publication in this journal is cited, in accordance with accepted academic practice. No use, distribution or reproduction is permitted which does not comply with these terms. 